\title{
A rare case of caesarean scar ectopic pregnancy: a case report
}

\author{
Hiremath P. B., Vinothini Anandabaskar*, Nivedhana Arthi, Rohini E., Indu N. R.
}

Department of Obstetrics and Gynecology, SVMCH and RC, Puducherry, India

Received: 14 January 2020

Accepted: 07 February 2020

\section{*Correspondence:}

Dr. Vinothini Anandabaskar,

E-mail: vinothinibaskar37@gmail.com

Copyright: () the author(s), publisher and licensee Medip Academy. This is an open-access article distributed under the terms of the Creative Commons Attribution Non-Commercial License, which permits unrestricted non-commercial use, distribution, and reproduction in any medium, provided the original work is properly cited.

\section{ABSTRACT}

Scar ectopic pregnancy is a condition where the gestational sac implants into the previous caesarean scar site. Although it is a rare entity, its incidence is increasing due to rising rates of caesarean deliveries. Here authors report a case of caesarean scar ectopic pregnancy managed by laparotomy with caesarean scar ectopic excision following failed medical management. The patient recovered without any intraoperative or postoperative complications. An early diagnosis and management are vital in preventing maternal morbidity and mortality.

Keywords: Ectopic pregnancy, Hysterectomy, Laparoscopy, Laparotomy, Methotrexate, Scar, Vasopressin

\section{INTRODUCTION}

Ectopic pregnancy is a condition where the gestational sac implants outside the uterine cavity. The ectopic gestation can implant in the fallopian tube, ovary, cervix, abdominal cavity or previous caesarean scar. The commonest site of implantation is the ampulla of the fallopian tube. The risk factors for ectopic pregnancy are tubal surgeries, prior ectopic pregnancy, pelvic inflammatory disease and use of artificial reproductive techniques. The classical triad of ectopic pregnancy is abdominal pain, vaginal bleeding and amenorrhoea. Ectopic pregnancy contributes to nearly $6 \%$ of pregnancy related deaths. ${ }^{1}$

Scar ectopic pregnancy is a condition where the gestational sac implants into the previous caesarean scar site. ${ }^{2}$ The incidence of scar ectopic pregnancy is 1 in $2000 .^{3}$ This entity is rare but its incidence is rising due to the increasing rates of caesarean deliveries. ${ }^{4}$

Scar ectopic pregnancy is caused by endometrial and myometrial disruption due to previous caesarean section. ${ }^{5}$ This condition can cause high maternal morbidity and mortality. Caesarean scar ectopic pregnancy can be complicated by uterine rupture, life threatening haemorrhage and morbidly adherent placenta. ${ }^{6}$ The gestational sac implanted in the caesarean scar can invade into the bladder further complicating the condition and can lead to operative difficulties. ${ }^{6}$ Thus an early diagnosis and management is vital in preventing maternal morbidity and mortality.

\section{CASE REPORT}

A 28-year-old G4P1L1A2 with previous LSCS came to antenatal OPD of Sri Venkateshwaraa Medical college and research institute, Puducherry with complaints of spotting per vaginum at 9 weeks 3 days of amenorrhea and outside ultrasound report of gestational sac in the lower segment suggestive of missed abortion.

Patient was stable on physical examination. No abnormality was detected on per abdominal and per vaginal examinations.

Repeat ultrasound (Figure 1) revealed a single fetus of 7 weeks 1day located eccentrically in the lower uterine segment adjacent to the previous caesarean scar. The same findings were confirmed by MRI pelvis (Figure 2). 
The serum $\beta \mathrm{HCG}$ value on admission (day 1) was 583 $\mathrm{mIU} / \mathrm{ml}$. The decision for medical line of treatment was taken, hence Inj. Methotrexate $50 \mathrm{mg}$ IM was given. The repeat serum $\beta \mathrm{HCG}$ value after 48 hours (day 3 ) showed significant increase in the value $(68594.5 \mathrm{mIU} / \mathrm{ml})$ following which a second dose of inj. Methotrexate 50 $\mathrm{mg}$ with tab. Mifepristone $400 \mathrm{mg}$ was given. The repeat serum $\beta H C G$ value on day 5 was found to be decreased by $40 \%(37228 \mathrm{mIU} / \mathrm{ml})$ but an increase in the gestational sac size with persistent cardiac activity was noted. In view of the above inconsistent finding, the decision for laparotomy with consent for hysterectomy was taken.

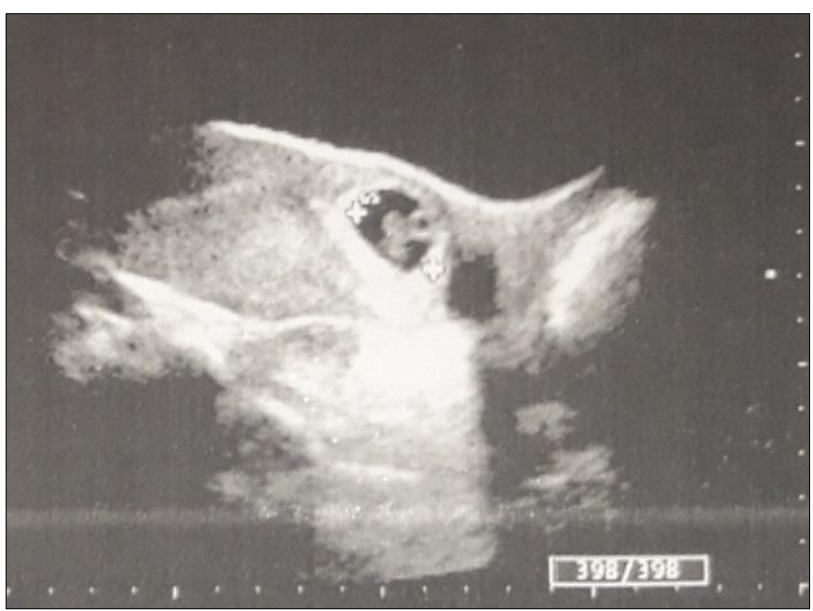

Figure 1: USG image of the gestational sac in the previous scar site with obvious thinning of the myometrium.

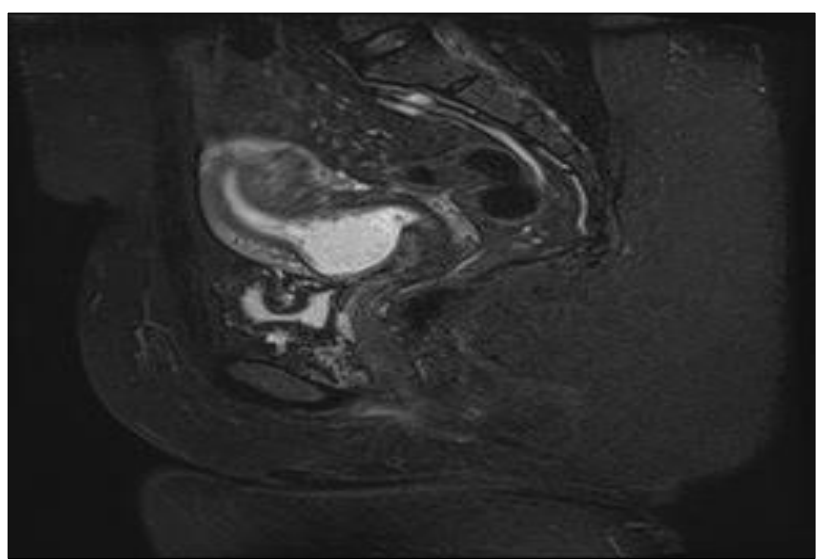

Figure 2: MRI pelvis image showing the scar ectopic gestation.

Intraoperative findings (Figure 3 - 4), the uterus was of normal size with an evidence of bulge seen anteriorly in the lower uterine segment beneath the bladder and no signs of ectopic rupture. Bilateral uterine arteries were ligated at the entry level and inj. Vasopressin 5 units mixed with normal saline was injected around the bulge. Incision was given at the site of implantation of the ectopic pregnancy and the same was evacuated. The uterine rent was closed in layers and complete hemostasis was secured. No intraoperative and postoperative complications were present.

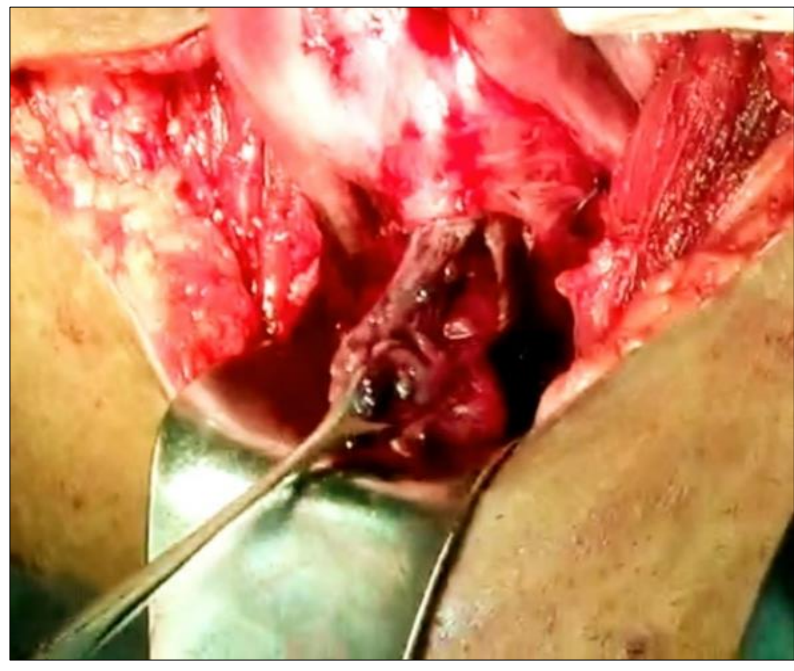

Figure 3: Products of conceptus removed by a small transverse incision.

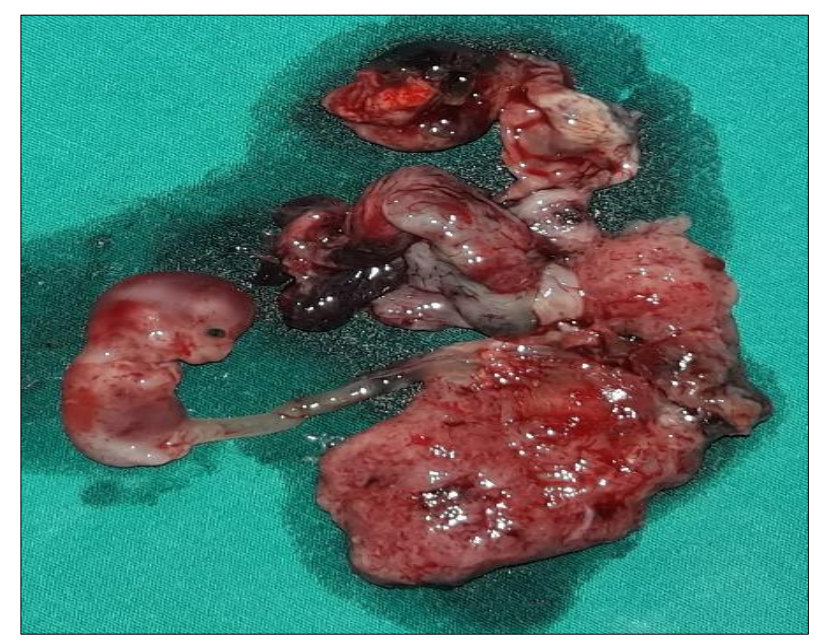

Figure 4: The fetus along with the umbilical cord and placenta.

Patient's recovery was good and she was discharged after 6 days. On follow up after 6 weeks she had no complaints.

\section{DISCUSSION}

A high clinical suspicion of scar ectopic is required in all early pregnancies with previous caesarean delivery presenting with painless vaginal bleeding. ${ }^{1}$

The presence of cardiac activity is a poor prognostic factor due to the increased risk of complications. Uterine rupture was seen in $9.9 \%$ of scar ectopic pregnancy with cardiac activity. ${ }^{7}$ Ultrasound is the main stay in the diagnosis of scar ectopic pregnancy. The ultrasound 
criteria for the diagnosis of scar ectopic pregnancy include the gestational sac or placenta attached to the site of previous caesarean scar with myometrial thinning with empty uterine cavity, closed and empty cervical canal. Colour flow Doppler shows a low velocity and high impedance blood flow. ${ }^{5}$

The management of scar ectopic pregnancy can be expectant, medical or surgical management. Expectant management can be an option for anembryonic scar ectopic patients as $70 \%$ have uncomplicated spontaneous abortions. ${ }^{7}$ The various medical and surgical treatment modalities available are intramuscular methotrexate or etoposide administration, oral mifepristone, ultrasound guided intra-gestational injection of $\mathrm{KCl}$ or methotrexate or vasopressin, uterine artery embolization, dilatation and curettage, hysteroscopic excision, laparoscopic excision, laparotomy and excision, hysterectomy. ${ }^{4}$ The above treatment modalities can be combined to improve the treatment success rate.

Management with methotrexate alone is recommended when serum levels of betaHCG is less than $5000 \mathrm{IU} / \mathrm{L}$ with the gestational sac less than 8 weeks. ${ }^{5}$ Medical management with methotrexate alone showed $62.1 \%$ complication rates. ${ }^{4}$ Dilatation and curettage are preferred when the myometrial thickness is at least $2 \mathrm{~mm}$ otherwise an abdominal or laparoscopic resection is preferred. ${ }^{5}$ However the surgeon's and patient's preference plays a major role in deciding the treatment modality.

In a case report by Ajong et al, ruptured scar ectopic was managed by emergency laparotomy. Intraoperatively around 2 litres of hemoperitoneum was noted. ${ }^{8}$

In a case report by Dhillon et al, a post IVF patient opted to continue the pregnancy and delivered a live baby of 1450 gms by classical caesarean section at 33 weeks of gestation. Hysterectomy was done due to adherent placenta. $^{9}$

In another case report by Fatusic et al, scar ectopic pregnancy presented with severe bleeding per vaginum after 1 month of dilatation and curettage. Hysterectomy was done and histopathology revealed placenta percreta. ${ }^{10}$

Funding: No funding sources Conflict of interest: None declared

Ethical approval: Not required

\section{REFERENCES}

1. Brancazio S, Saramago I, Goodnight W, McGinty K. Cesarean scar ectopic pregnancy: case report. Radiol Case Rep. 2019;14:354-9.

2. Jayaram PM, Okunoye GO, Konje J. Caesarean scar ectopic pregnancy: diagnostic challenges and management options. Obstet Gynaecol. 2017;19:1320.

3. Odgers HL, Taylor RAM, Balendran J, Benness C, Ludlow J. Rupture of caesarean scar ectopic pregnancy: a case report. Case Reports Women's Health. 2017; 14:8-10.

4. Timor-Tritsch IE, Monteagudo A, Unforeseen consequences of the increasing rate of caesarean deliveries: early placenta accrete and caesarean scar pregnancy. A review. Am J Obstet Gynecol. 2012;207(1):14-29.

5. Jayaram PM, Okunoye GO, Konje J. Caesarean scar ectopic pregnancy: diagnostic challenges and management options. The Obstet Gynaecol. 2017;19:13-20.

6. Majangara R, Madziyire MG, Verenga C, Manase M. Caesarean section scar ectopic pregnancy - a management conundrum: a case report. J Med Case Rep. 2019;13:2069-9.

7. Cali G, Timor Tritsch IE, Palacios Jaraquemada J, Monteaugudo A, Buca D. Outcome of caesarean scar pregnancy managed expectantly: systematic review and meta-analysis. Ultrasound Obstet Gynecol. 2018;51:169-75.

8. Ajong AB, Kenfack B, Agbor VN, Njotang PN. Ruptured caesarean scar ectopic pregnancy: a diagnostic dilemma in a resource-limited setting. BMC Res Notes. 2018;11:292.

9. Dhillon AS, Sood S. Caesarean scar pregnancies, diagnosis and management. Int J Reprod Contracept Obstet Gynecol. 2018;7(4):1592-6.

10. Fatusic J, Hudic I, Moralic AZ, Hadziefendic B. Cesarean scar pregnancy complicated with placenta percreta. Med Arch. 2019;73(1):58-60.

Cite this article as: Hiremath $\mathrm{PB}$, Anandabaskar V, Arthi N, Rohini E, Indu NR. A rare case of caesarean scar ectopic pregnancy: a case report. Int J Reprod Contracept Obstet Gynecol 2020;9:1315-7. 